\title{
The traditional-faculty supervised teaching model: Nursing faculty and clinical instructors' perspectives
}

\author{
Florence Loyce Luhanga* \\ Faculty of Nursing, University of Regina, Canada
}

Received: November 30, 2017

DOI: $10.5430 /$ jnep.v8n6p124
Accepted: January 8, 2018

Online Published: January 21, 2018

\begin{abstract}
Background: The clinical instructors (CI) is an integral part of a quality clinical learning experience. CIs assist nursing students to integrate theory into practice. The traditional faculty-supervised model (traditional model) is used in Canadian undergraduate nursing programs for clinical teaching of Year 1 to 3 students, i.e., one CI supervises 6 to 8 (or 10) nursing students. Some researchers have questioned the effectiveness of the model in preparing students for practice and have concluded that in its current form, it might not be "best practice" with respect to student learning and patient safety. Research is needed to evaluate the traditional model of clinical instruction.

Methods: This study explored perceptions and experiences of full-time faculty and CIs who teach and supervise students using the traditional model; and to identify the strengths and challenges of the model with regard to student learning and patient safety. The sample comprised of five faculty and seven CIs. Using an exploratory descriptive approach, qualitative data were gathered through semi-structured interviews and analyzed using thematic content analysis.

Results: Although both faculty and CIs described some positive experiences facilitating nursing students' learning within the traditional model, participants indicated that their experiences depended on the size and complement of the clinical group. Overall, participants perceived more challenges than strengths with the model. Strengths included: (a) peer learning and support, (b) instructors' familiarity with curriculum and evaluation process, (c) guidance and support for novice students, (d) instructors' control over students' learning, and (e) opportunity for clinical experiences in a variety of settings. Challenges included (a) managing large clinical groups, (b) missed learning opportunities, (c) limited time for teaching and supervision, (d) difficulty balancing student learning with patient safety, (e) being seen as visitors on the unit, and (f) lack of role preparation.

Conclusions: These findings provide additional evidence to existing knowledge related to clinical education of nursing students. Recommendations for improving the quality of clinical experiences and support for CIs are presented as a means for mitigating some of the challenges of using the traditional model of instruction.
\end{abstract}

Key Words: Traditional model, Clinical experience, Nursing faculty, Nursing clinical instructors, Qualitative method

\section{INTRODUCTION}

Nursing education programs have a responsibility to ensure students are exposed to the realities of the contemporary healthcare system and to prepare them for practice with competencies necessary to promote and preserve patient safety. ${ }^{[1]}$ The Institute of Medicine (IOM) ${ }^{[2]}$ and others ${ }^{[3]}$ suggest that clinical education has simply not kept pace with recent changes within the healthcare system, shifting patient demographics, and scientific advances. New graduate nurses often report feeling unprepared for the complexity of current nursing practice. ${ }^{[3-5]}$ Evidence suggests that these trends require changes in the way clinical education is provided

*Correspondence: Florence Loyce Luhanga; Email: florence.luhanga@uregina.ca; Address: Faculty of Nursing, University of Regina, Canada. 
to better prepare new nurse graduates for the complexity of current health care practices. ${ }^{[2,3]}$

The clinical experience is an integral component of undergraduate nursing education program..$^{[1,3,6]}$ In preparation for clinical experience, students are taught and practice the required nursing skills in the clinical skills laboratory under the supervision of a university or college instructor. According to Skelton-Green and Baumann (as cited in CASN, 2004), nursing students in Canada are required to spend about 2,000 hours in clinical practice as part of their Bachelor of Science in Nursing program. Clinical experiences provide students the opportunity to acquire the knowledge, skills, and values required for practice and to become socialized into the nursing profession. ${ }^{[6]}$ The traditional model is used by most undergraduate baccalaureate nursing programs in Canada. ${ }^{[1,7,8]}$ Typically the model involves a clinical instructor (CI) who is a registered nurse (RN) employed by the educational institution, who oversees 8 to 10 nursing students, each caring for one or two patients. ${ }^{[3,7]}$ The CI is responsible for overseeing the teaching and learning process, the development of patient assignments, and conducting students' evaluations throughout the duration of clinical placements. In addition, the $\mathrm{CI}$ acts as a coach and role model. ${ }^{[7]}$ However, despite documented shortcomings of the model and a lack of empirical studies confirming its effectiveness in preparing students for the complexity of professional practice, the model is still widely used internationally. ${ }^{[3,9,10]}$

Stakeholders' perspectives of the traditional model can assist nursing programs to develop new clinical teaching practices and models for clinical education based on identifying strengths and overcoming limitations of current approaches. ${ }^{[11]}$ Thus, the purposes of the larger descriptive qualitative study were to explore nursing faculty, CIs' and nursing students' perceptions of their experiences in teaching/learning within the traditional model and to identify strengths and challenges of the traditional model with regard to student learning, while promoting patient safety. In this paper only the faculty and CIs' perspectives are presented.

\section{Literature review}

The traditional model has been viewed as the "gold standard" model for clinical education for decades. ${ }^{[12,13]}$ The assumption is that CIs who have the knowledge of the educational curriculum, ${ }^{[14,15]}$ well-developed clinical teaching skills ${ }^{[16]}$ and are committed to research based practice ${ }^{[15]}$ will be able to directly supervise students as they perform skills, document patient care, and interact with clients, family members, and clinical staff. ${ }^{[17,18]}$ Emerson, ${ }^{[19]}$ explained that theoretically, the model provides the CI with maximum control over both student's learning and evaluation. They guide the

Published by Sciedu Press students' thinking and acting, and assure accuracy and thoroughness. There is the sense that students are learning what they need to know at the appropriate level.

While the traditional model implies direct supervision by a qualified CI, literature has shown that due to high studentto-instructor ratio, the model does not guarantee the level of supervision, support, and attention that most junior students need to succeed and provide safe patient care. ${ }^{[12,14,15]} \mathrm{Sev}$ eral other concerns have been raised as to the extent, to which the traditional model prepares students for the realities of the current clinical environment ${ }^{[3,7,12,13]}$ including but not limited to brief or limited student-faculty interactions, increased patient acuity, inefficient use of student' time, and issues related to patient safety. ${ }^{[12,13,17,20,21]}$ The increased patient acuity and shorter lengths of stay, for example, have resulted in nursing units that are fast-paced, specialized, and technologically intensive which have increased the need for closer supervision of students. ${ }^{[7,13,17,20]}$ Moreover, these changes prevent CIs from effectively supervising 8-10 students who are responsible for 8-10 patients in the acute care setting. This, in turn, results in limited individual student attention and restricted learning opportunities for students. ${ }^{[7,13,17,20]}$

Additionally, due to large clinical groups, CIs spend most of their time supervising students performing tasks, resulting in a lack of time to effectively help students develop critical thinking and decision-making skills, and process the rationale for nursing interventions. ${ }^{[10,22]}$ Inadequate supervision has been associated with medication errors among nursing students. ${ }^{[23-26]}$ For example, previous studies by Searl-Reid, et al. ${ }^{[25,26]}$ and Dolansky et al. ${ }^{[24]}$ revealed that nursing students do not always receive the level of supervision that is legally required and that this was identified as the leading to medication errors or near misses. Reid-Searl et al. ${ }^{[25,26]}$ explored nursing students' experiences of administering medication in the clinical setting and found that approximately one third of the participants reported making an actual or "near miss" medication error. Where medication errors occurred, participants reported not receiving direct and appropriate supervision by a registered nurse (RNs) or CI. The findings from these studies further revealed that potential errors were identified by RNs nurses when direct supervision was provided. Safe administration of medication is an important component of skilled nursing practice, and nursing students require personal and supportive supervision from either the CIS or RNs to enhance learning and promote safety. It is important, then, that CIs provide the best possible supervision for students to succeed and become safe and competent practitioners.

The CI is an integral part of a quality clinical experience. 
CIs have an ethical and professional obligation to ensure that nursing graduates are adequately prepared with skills required to ensure safe, high-quality patient care ${ }^{[3]}$ Evidence from research on clinical education suggests that the CI's role is complex, given the need to balance two worlds: the academic world, which requires knowledge of the curriculum and student evaluation, and the clinical practice world, with an emphasis on providing quality student learning opportunities. ${ }^{[27]}$ To be effective in this role, the CI requires both clinical and teaching expertise. However, the high turnover of CIs, a shortage of faculty, and challenges of recruiting quality faculty into clinical teaching leads to hiring part-time CIs based on their clinical expertise and often with no teaching skills. ${ }^{[8,28,29]}$ Given the challenges identified with the traditional model as discussed here, and because of the limited research on the effectiveness of the traditional model as previously described, an exploratory descriptive study was undertaken to better understand nursing faculty and CIs perceptions of their experiences with respect to teaching and supervising students using the traditional model.

\section{METHOD}

\subsection{Research questions}

The research questions that guided this study were: (a) What are the perceptions and experiences of nursing faculty and CIs regarding teaching/supervising students within the traditional model of clinical instruction? (b) What are the strengths and challenges of the traditional model as articulated by participants? (c) What are the experiences of nursing faculty and CIs regarding student evaluation in the traditional model of clinical instruction? and (d) What suggestions/recommendations do participants have to improve clinical education for students while ensuring safe patient care?

\subsection{Sampling and recruitment}

Participants were recruited from two universities and one college in a western Canadian province, through the electronic distribution of a study information flyer. Purposive sampling was employed as the primary approach to recruit information-rich cases. ${ }^{[30]}$ In addition, participants were recruited using "snowball" technique. Potential participants were asked to contact the author or research assistant to set up a time and date of interview. The inclusion criteria for nursing faculty were: classroom faculty who teach [or have taught clinical] or oversee clinical experience, and CIs in Undergraduate Program teaching undergraduate students in years 1 to 3 and willingness to participate in an individual interview. Inclusion criteria for CIs were: active in clinical teaching during the past 12 months and willingness to participate in an individual interview. Twelve participants volunteered for the study: five were university faculty; five were full-time CIs (four employed by the college and one by the university) who taught both theory and clinical, and two were part-time CIs.

\subsection{Data collection}

Data were collected through semi-structured individual faceto-face interviews that lasted between 40-90 minutes. Interviews were conducted at a time and location that was convenient to both the participants and the researcher. The interview guide was developed based on the literature and the author's prior experience as a CI using a traditional model. Prior to each interview, demographic data were obtained from each participant, which included a question on how participants were prepared for their teaching role. Interviews were audio recorded and transcribed verbatim. Field notes of observations made during the interview process were also taken. Interviews were conducted until data saturation was achieved. ${ }^{[30]}$ A graduate research assistant, who signed a confidentiality statement, transcribed the responses. The researcher then reviewed each transcript against the original recording for accuracy.

\subsection{Data analysis}

Data analysis occurred simultaneously with data collection. After each interview, transcripts were generated and then the data analysis occurred. This process continued until data collection ended. Data were analyzed using thematic analysis ${ }^{[31]}$ and constant comparative analysis. ${ }^{[32]}$ Analysis involved becoming familiar with the data, generating initial codes, searching for themes, reviewing and naming themes, and producing the report. Although this article focuses on the perceptions of faculty and CIs, triangulation of findings from seven nursing students' interviews was also conducted to identify areas of agreement, areas of disagreement, and to validate themes from students. Results of this triangulation step will be reported in a subsequent paper.

\subsection{Ethical considerations}

Approval was obtained from the institutional ethics review boards of all the three participating academic institutions prior to data collection. Written informed consent was obtained from all the participants prior to being interviewed and audio-taped. Participants could withdraw from the study at any time without negative consequences. To ensure confidentiality, all transcripts were assigned a code and identifying information from transcripts or field notes were removed. All original data and field notes were secured in a locked filing cabinet. Upon completion of the study, code sheets containing participants' demographic information were destroyed. 


\subsection{Rigour}

The rigor or trustworthiness of the data were assessed for credibility, fittingness, auditability, and conformability. ${ }^{[33]}$ Credibility was achieved by collecting data from a variety of informants (university faculty, college nursing instructors, and sessional instructors). ${ }^{[34]}$ Fittingness was enhanced by collection of data from different settings. Excerpts from participant transcripts are presented to facilitate auditability of data analysis. ${ }^{[35]}$ Finally, the author kept an audit trail and theoretical memos to facilitate auditability and confirmability. ${ }^{[34]}$

\section{Findings}

Participants included five university faculty and seven CIs. Ten were female and two were male. All faculty members had PhDs, five CIs had master's degrees, and two CIs had Bachelor's degrees in Nursing. The majority of the participants $(83 \%)$ were in the $40+$ age group while two were in the 25-29 age range. The participants' years of teaching experience ranged between 3 to 38 years and clinical teaching experience ranged from 1 to 21 years.

In response to the first interview question, "What model(s) of clinical teaching are currently being used in your program?" All participants indicated that the traditional model was used for students in years 1,2 , and 3 . While the preceptorship model was used in some year 3 courses, it was predominantly used for students in year 4. Participants were then asked to describe their experiences within the traditional model. Perceptions of faculty and CIs are reflected in the following three interrelated themes: (a) satisfaction with the overall experience, (b) strengths of the traditional model, and (c) challenges of the traditional model. Subthemes are presented under each major theme to further clarify participants' comments. Based on their experiences, participants also provided recommendations for improving the quality of clinical experiences and support for CIs.

\subsection{Theme 1: Satisfaction with the overall experience}

Both faculty and CIs were generally satisfied with the traditional model. However, they acknowledged that sometimes working within this model was uncomfortable, difficult, challenging and too demanding of their time. They further explained that perceptions of satisfaction with the traditional model depended on factors such as the dynamic or complement of the clinical group. As exemplified in the following comments:

“... Sometimes it depends on the complement of students you get in clinical... So if I have certain student groups. If I have two ESL students... and another weaker student... I can't

Published by Sciedu Press spend enough time with everybody, right and I especially can't spend enough time with the ESL students, and sometimes they need a little more support not because they don't know the material, they often know their theory very well but it's the communication aspect." (Participant $1, \mathrm{CI})$

"It can be difficult and its always okay if six or eight of them [students] are functioning at a really good level, but if you have one or two that aren't, then you spend almost all your time with them and that makes clinical teaching quite difficult..." (Participant 10, Faculty)

\subsection{Theme 2: Strengths of the traditional model}

Participants described five main strengths of the traditional model: (a) peer learning and support, (b) instructional familiarity with curriculum and evaluation process, (c) guidance and support for novice students, (d) instructors control over students' learning, and (e) opportunity for students' experience in a variety of settings.

\subsubsection{Peer learning and support}

As exemplified in the following excerpts, six participants (three faculty and three CIs) identified peer learning, as one of the main strengths of the traditional model.

"I think it's a real opportunity for students to learn from other students in the group. So that's such an opportunity, really it is... quality of learning for students in a group of eight with one instructor, when they realize that that instructor is not responsible for all of their learning, they can learn from each other..." (Participant 9, Faculty)

“... another strength that the groups can learn from each other and they are not so scared when they are with a group and they are with their friends on a team coming into the unit and they can work together..." (Participant 11, CI)

\subsubsection{Instructors' familiarity with curriculum and evalua- tion process}

Four participants (three faculty and one CI) identified that the traditional model guaranteed CIs possess the conceptual clarity and knowledge of theory-practice links needed to support students. As a result, students can be taught and evaluated by $\mathrm{CI}$ with experience in teaching theory and practice:

"Well the advantages of it [traditional model] are that you can be, conceptually guaranteed that the instructor will be able to teach the theoretical concepts in the clinical area... whereas 
in other models you might not have that. Because you know your instructors are generally are well versed with the curriculum and they can help the students make the theory research links so I think that's one of the greatest advantages." (Participant 2, Faculty)

The same faculty further acknowledged that not all instructors are familiar with the curriculum and the evaluation process.

"I'd say that the instructors can evaluate the curriculum and the way the curriculum is being taught very well. I wouldn't deny that and this is only some instructors, too, that there are some, they don't understand the curriculum well and how to bring the research practice links." (Participant 2, Faculty)

\subsubsection{Guidance and support for novice students}

Six participants (three faculty and three CIs) stated that because novice students lack experience, particularly with regard to communication with patients and staff nurses, the CI role in the traditional model provided novice students with a consistent person to obtain guidance and support. That is the CIs were consistent go to person:

"They are really green in year one. I mean they are afraid to even walk into the patient's room. . I've had to take the students by the hand and say come on, let's go, it's ok. They don't know what questions to ask." (Participant 3, CI)

“... students have a constant person to go to, you know give them good feedback on say sterile technique... and really helping them join the theory. I think it's a real advantage for the students to have a faculty member on the unit with them at all times. And certainly in year one, we would want to see those for sure... in terms of patient safety too..." (Participant 4, CI)

"I taught in second year, first semester, they were very novice so at that point they had only done bed baths and they hadn't done medication, you know... some of them were even, what I'd say, cautious even talking with people so you have to really...they need support in organization, assessment... I think that model [Traditional] about where we are mothers and we've got eight little ducklings, you know that's may be good for really novice... but I think as they gain into second year, I think we need to cut those apron strings..." (Participant 5, Faculty)
The same participant commented that students need emotional support especially when they encounter difficult situations.

"I remember a student, she got yelled at and so she was, she took it very personally and was crying and was upset and, you know. I had to talk with her and to let her sort of work through that. Having said that though, you know, when you're in acute care and someone dies and that's the first time for a student, umm, you know, you have to process that with them as well..." (Participant 5, Faculty)

\subsubsection{Instructor's control over students' learning}

Four participants (two faculty and two CIs) commented that in the traditional model, CIs have more control over the students learning, as they can directly observe and stay close to students:

"The advantage is I get to see, work with them, one to one. I'm not relying on somebody else and I think probably I'm more of a control freak that way. .. I think that an advantage to it is that I get to see you, I do watch with you, it might take me long time, I might miss all my breaks but I will go with you and do that dressing change and I know that you will be following the protocol. Yeah I'm sure there are shortcuts that you can take but you could learn those later... you're learning and you're going to follow what you have been taught in school, and I do that..." (Participant 8, CI)

"Well because you were right there. . . So I think that would be probably one of the strengths about that model, you get to see in most cases, you know what's going on you get to see those opportunities, how they are growing... so if you are a person that likes control (laughs) that's probably a good clinical model for you..." (Participant 5, Faculty)

\subsubsection{Students' experience in a variety of settings}

Another strength identified by two CIs was that students experience clinical learning in a variety of settings and gain general familiarity with multiple units when being taught in the traditional model. As illustrated in the following comment:

"The only strength is you do it for three years so you can a see a multi variety of settings... so 
the students get a general familiarity about pediatrics, obstetrics, general surgery, medicine, umm cardiac units, mental health. They go to every single unit so that is a strength cause they move from one place to the next to kind of understand a variety of areas in nursing." (Participant $11, \mathrm{CI})$

\subsection{Theme 3: Challenges of the Traditional Model}

Participants described six challenges associated with the traditional model: (a) managing large clinical groups, (b) missed learning opportunities, (c) limited time for teaching and supervision, (d) difficulty balancing student learning with patient safety, (e) being seen as visitors on the unit, and (f) lack of role preparation.

\subsubsection{Managing large clinical groups-"Can't be in several places at once."}

Large clinical groups were the most frequently mentioned barrier to both faculty and CIs' ability to facilitate student learning and monitor and evaluate student clinical performance. High instructor-to-student ratios decreased time available for individual student-instructor interactions. As evidenced by comments from CIs and faculty, both groups described the ratio of $1: 8$ as too high and expressed concerns that the ratio makes instructors' tasks difficult to complete:

"Well sometimes you are really running. At [name of agency] I have students in palliative care, convalescence and long term care... So you really have to be available for the students. Usually I carry a cell phone. So if the students really need me for a skill, then they call me and I am there for them..." (Participant 3, CI)

"I can't be in everybody's room... and so the disadvantage to that is, you have eight students, you can't be in every person's room you now with them, with every patient..." (Participant 8 , CI)

\subsubsection{Missed learning opportunities}

All participants commented that because of the high studentinstructor ratios, students were likely to miss learning opportunities while waiting for the instructor to come and observe or help them with procedures:

"I remember as a student, like you're waiting a long time, you're always waiting for the instructor. Waiting, waiting, waiting. You miss opportunities, right..." (Participant 7, Faculty)

"It's at a certain cost though because I don't think that CIs have eyes everywhere and many
CIs have been told by students that, I really wanted to perform a certain skill but I couldn't find you or I couldn't get you or it wasn't my time with you so I wasn't able to do that and sometimes things pop up on the unit that were not prior scheduled that would've maybe been a good learning opportunity..." (Participant 9, Faculty)

\subsubsection{Limited time for teaching and supervision}

All participants described how they had to work within time constraints. The CI had to go back and forth among the nursing students and was sometimes needed by multiple students at the same time. At times CIs did not take breaks so as to ensure that students were not being left unattended.

"As a CI, I feel I don't have enough time with each of the students to teach them everything that they should know. I feel as instructors for third year, we have to teach in obstetrics and it's a short, short time, it's only six weeks and so they are cramming a lot of knowledge and it works out ok but we have too many students for one nurse... seven students is a lot..." (Participant 11, CI)

"Many of the people that I know that take students into clinical areas as nursing students say they don't take breaks, the instructors don't take breaks, they don't ever leave a student on a unit unattended so they need to know where the students are all the time and what they are doing and they make sure that, umm, they supervise any, any new skills.” (Participant 9, Faculty)

Another major concern related to limited time for supervision was that one weak student decreases time for supervision of all students in a clinical group. The majority of participants commented that the model might work well if all the students are doing reasonably well. However, if one student is struggling, this reduces the availability of the instructor to supervise the other students in the group as the instructor spends a great deal of time on the weaker student at the expense of the stronger students:

"... if you have a student who needs more guidance and support, you pull away from the learning experiences of the rest of the group and although we are told by our faculty if we need somebody else to come help on the unit, you do get by but its still, it's hard to be in all places at once and I found even as a student, you find that you can never find your teacher cause your 
teacher or your CI is always with the students, cause they are one person. They can't be in six places at once" (Participant 12, CI)

"In my opinion [the model] has serious challenges for the student and the instructor, and just the idea of one person looking after seven or eight students, I mean the assumption is, and I think it works well when the students are reasonably good. But when there's a problem or a challenge or some very weaker students, the whole model, I think doesn't, starts to collapse and the instructor spends a great, great deal of time with the weaker students to the determent of the stronger students, actually, you know, or students in between" (Participant 7, Faculty)

\subsubsection{Difficulty balancing student learning with patient safety}

All participants commented that they felt responsible and accountable for patient safety and quality of care as well as for supervising students' learning. As a result, they described their challenges with the responsibility of balancing good learning opportunities and safe quality care for patients:

“... as an instructor I've always felt that I am responsible for all of the patients that have been assigned to the students and I assign them. I've went around and met all the patients before I assigned students to care for this patient for this number of hours in a day, so I always feel that I am responsible for the patients. So I am also dually aware that I am responsible to support the student learning but I am also responsible and accountable for the patient safety and for the quality of care, that is being provided to that patient, while the students are looking after them and I'm supervising the students ... So it's a balancing act between providing good learning opportunities for students but also providing safe quality care for the patients that the CI assumes responsibility for... So I find that it's hard." (Participant 9, Faculty)

\subsubsection{Being seen as visitors on the unit}

Some participants reported that they were treated like guests in clinical settings and were rarely accepted as members of the nursing team:

"I think that would be in terms of the most, the weakness of that model is that you are just sort of this visitor that pops in and the other thing, it didn't happen often because there's this perception that nursing students are laborers so ah because the units were so busy so that they were there purely as laborers..." (Participant 5, Faculty)

"If you don't know the staff really well, like I didn't this winter. . i it's a little more challenging. Fortunately the students I had didn't, couldn't do anything unsafe... So, it just depends on how familiar are the CIs in the area." (Participant 2, Faculty)

One CI explained how she constantly updated herself with a patient's progress as she believed that students still lacked critical thinking and did not trust some of the nurses with the patient progress charts:

"I continuously go back and check all of the patient's charts to make sure everything looks good because, for example if a student finds a baby's temperature to be 36.1 and they don't report that to me and I find that later, that's not good but the student doesn't have that critical thinking sometimes there to think, this could be a issue, lets deal with it. The nurses sometimes don't check those charts either so, that's why I always go and check back on the charts..." (Participant 11, CI)

\subsubsection{Lack of role preparation}

Almost all the faculty and CIs indicated that they did not receive any formal preparation for clinical teaching.

"I have been working with the university of [Name] so I went right from the hospital into the clinical areas without any kind of training, there's no orientation, no there is orientation to the university as to how do you grade a student, that type of thing but there was little on how do you become a CI and I have to say I was scared to death..." (Participant 8, CI)

“... we don't prepare them for it [clinical teaching and evaluation] and it's quite different to the difficult situation they're working in the hospital. Plus, they are sort of; they've two bosses you know. They are working at the hospital in a clinical area for the staff and they are working for us over here and sometimes those expectations don't coincide really well and I found too that they, the CIs, like they weren't prepared... They really like to give benefit of the doubt." (Participant 2, Faculty) 
Participants noted that lack of formal training contributed to issues such as new CIs "giving the benefit of the doubt" to some students, CIs quitting because they do not know how to manage weak students, or CIs being unable to manage large clinical groups.

"They really, they like to give benefit of the doubt. I'm, I certainly don't do that very often because I, I think that, you know as you become more seasoned like I am too old, you have pretty good intuition to whether a student is going to do well or not and so, like I can just say, well if you pass them, they'll just fail next year, you know, so, why are we. [What's the point] postponing the inevitable, let's do it now, so.” (Participant 2, Faculty)

The same participant commented that some CIs quit because they do not know how to manage weak students.

"well and I find with the CIs saw this happen often, if we had a student who's weak and had some problems with progress, the CIs didn't know how to handle it. You know they don't want to handle it, didn't know how and if they were forced to do it that was usually the last time we ever saw them and they didn't come back again.” (Participant 2, Faculty)

"Seeing that we have such a high turnover of people in clinical and sometimes because we give them too many groups, right. Clinical isn't valued. I don't think, umm and the time a clinical teacher spends correcting concept maps, care plans, nursing interventions or a student's med research or journal, that's not valued, that's not accounted as part of my work." (Participant 1, CI)

Lastly, participants provided recommendations to strengthen the clinical learning experience. These recommendations focused on addressing the identified challenges.

\section{Discussion}

Study findings revealed that although both faculty and CIs were overall satisfied with teaching in the traditional model, participants acknowledged that sometimes it can be "uncomfortable", "difficult", "challenging", and "busy". Similarly, a study by Nishioka, Coe, Hanita, and Moscato ${ }^{[36]}$ compared the perceptions of nurses who participated in the clinical education of students using traditional and dedicated education unit (DEU) models, nurse educators indicated that they

Published by Sciedu Press enjoyed teaching in traditional unit but "it was hard work" and "slowed" them down" (p. 296).

Depends on the size of the clinical group. The instructor-tostudent ratios varied between 1:6 and 1:8, depending on the nature of the clinical practice setting and the students' year of the study. Although these ratios were similar or even lower compared with those reported in the literature ${ }^{[3,7,10,36]}$ both faculty and CIs perceived these instructor-to-student ratios as a major challenge that impacted on their level of satisfaction with the traditional model. Participants described the ratio of 1:8 as too high, suggesting it makes the CIs' tasks too difficult to manage and impacts negatively on their satisfaction and ability to effectively facilitate and evaluate student learning. Supporting these concerns, other studies found that CIs' ability to facilitate student learning is affected when instructing large clinical groups. ${ }^{[3,10,12]}$ Benner et al., ${ }^{[3]}$ for example, reported that CIs struggled with the number of students (usually ranging from 8 to 10 students) in clinical rotations. Similarly, Ironside and McNeils ${ }^{[10]}$ revealed that finding time to provide appropriate guidance and supervision to each student in a large clinical group was the biggest challenge for CIs. Nishioka et al. ${ }^{[35]}$ reported that many clinical teachers stated that even though they enjoyed teaching in the traditional model, they found it hard and that "it slowed them down" (p. 296).

Depends on the complement of the group. Participants reported that clinical instruction in the traditional model is effective when all the students in a group function fairly well. However, it becomes very challenging for them, for example, when there are weaker students or English as a second language (ESL) students who may have a language barrier. Several authors have affirmed that the language problems that ESL students experience may have a negative effect on their academic achievement in nursing programs. ${ }^{[37,38]}$ For example, Starr ${ }^{[38]}$ asserted that the language barrier experienced by ESL students can affect their ability to acquire the needed resources to continue their education, and may also lead the CI to assume that ESL students are less intelligent. Studies have revealed that ESL students may experience challenges in clinical settings with the use of terminology, communicating or understanding patient requests, or providing explanations. ${ }^{[39,40]}$ In a study by Bosher and Smalkoski, ${ }^{[39]}$ when ESL students communicated with patients, CIs noted lack of eye contact, low volume speech, and inappropriate voice intonation. Therefore, as Starr ${ }^{[38]}$ suggested, a positive instructor's response to language challenges is crucial to ensuring the learning of the continuing growing numbers of nursing students from culturally diverse backgrounds. For example, CIs need to increase their own cultural awareness, sensitivity and competence. ${ }^{[38]}$ 


\subsection{Strengths of the Traditional Model}

Participants in this study identified five strengths of the traditional model: (a) peer learning and support, (b) instructional familiarity with curriculum and evaluation process, (c) guidance and support for novice students, (d) instructors control over students' learning, and (e) opportunity for students' experience in a variety of settings.

Peer learning and support. Peer learning and support were identified as one of the benefits of the traditional model. Participants believed that the model provides opportunities for students to learn from each other, which facilitates learning particularly when the CIs are not readily available. Similarly, several authors ${ }^{[41-43]}$ have identified peer learning and peer support as critical aspects of a positive clinical learning experience. Peer learning enables students to share ideas, solve problems, and experience clinical reasoning together, which in turn promotes self-directed learning, ${ }^{[43]}$ a sense of independence, and increases students' confidence and decreases anxiety. ${ }^{[43,44]}$ Stone et al., ${ }^{[42]}$ however, caution that during peer learning activities, the need for student supervision remains important. Additionally, if peers are not knowledgeable or do not have the appropriate skills, then they cannot accurately pass information on to other students.

Instructors' familiarity with curriculum and evaluation process. A second benefit of the traditional model as perceived by participants in this study was the opportunity for students to be supervised by instructors who are familiar with the program's curriculum and evaluation process. The traditional model assumes that the CI will have the knowledge of the curriculum ${ }^{[15]}$ demonstrate effective clinical teaching skills, ${ }^{[16]}$ and possess clinical expertise and competence to directly supervise students as they perform the required skills. $^{[16,18]}$ Gaberson, Oermann, and Shellenbarger ${ }^{[45]}$ affirm that because CIs are involved to varying degrees with the curriculum, they can carefully select clinical activities that best meet the students' learning needs and which are consistent with the course goals and objectives. However, with the current shortage of faculty, nursing programs are increasingly relying on sessional or part-time CIs who may lack experience as educators, ${ }^{[46,47]}$ or clinical staff who may not know the students or have little experience in guiding students, thus requiring ongoing education, support and development. ${ }^{[46,48,49]}$ Similarly, participants in this study reported a lack of formal preparation and orientation to their teaching role.

Given the lack of preparation, orientation, and support for their clinical teaching role, participants, like others in previous studies reported that they learned to teach by trial and error or teach as they were taught. ${ }^{[48,50]}$ Participants fur- ther identified several strategies to assist CIs in transitioning and excelling in their new teaching role. These strategies include formal preparation and orientation sessions; mentorship particularly for new CIs; provision of required resources; inclusion of CIs in faculty meetings, events, and professional development activities; and ongoing support, which are all congruent with those in the literature. ${ }^{[29,48,49,51]}$ It is imperative that the full time faculty prepare and orient part-time faculty and CIs so that they are not only aware of their roles and responsibilities but also understand how the course relates to the overall nursing curriculum. ${ }^{[45]}$ Roberts et al. ${ }^{[49]}$ add that providing a rich and supportive environment for sessional CIs during their first clinical experience as an educator is crucial to developing and retaining nurse educators who can provide quality clinical education and fill the growing number of vacancies that will occur over the next decade.

Guidance and support for novice students. Congruent with findings from other studies, a third benefit was the support and guidance provided to beginning students ${ }^{[52,53]}$ particularly during the first placement. ${ }^{[54]}$ Evidence suggests that initial clinical experiences for undergraduate nursing students can be stressful and anxiety provoking and can interfere with the quality of clinical learning outcomes. ${ }^{[55,56]}$ In addition, Nordgren et al. ${ }^{[57]}$ explained that concerns related to quality teaching, safety, and evaluation tend to be more important for beginning students than for more advanced students. Therefore, the guidance and supportive learning environment created by $\mathrm{CI}$ is pivotal in maximizing the quality of clinical learning outcomes, particularly for novice students. Although the traditional model provides potential for direct supervision by a qualified CI, previous research revealed that the model does not guarantee or promote the level of supervision, support, and attention that most junior students need to succeed and provide safe patient care. ${ }^{[3,12]}$

Instructor's control over students' learning. On the other hand, participants suggested that the traditional model provides CIs with more control over the student learning, as they can directly observe and stay close to students. The traditional model allowed them to identify students' skills, observe their progress overtime, and adjust their own expectations to accommodate the learning needs of the students. These finding concur with the literature that the traditional model provides the CI with maximum control over both student's learning and evaluation. ${ }^{[19]}$ Beeman, ${ }^{[17]}$ however, cautioned that the higher level of supervision required of junior level students may hinder CIs from relinquishing some of their control to clinical staff on the units, particularly in acute care settings.

Student's exposure in a variety of settings. Another benefit 
of the traditional model was that students are exposed to a variety of clinical settings and gain familiarity with multiple clinical units. Nordgren et al. ${ }^{[57]}$ concur that this model has the advantage of flexibility in moving students from one clinical learning experience to another. Conversely, Newton, Cross, White, Ockerby, and Billet ${ }^{[58]}$ found that students who complete their second and third year clinical placements in a single organization showed enhanced learning engagement. Not having to re-orientate to different clinical setting each time they attend a clinical placement offers greater confidence and increased engagement in the clinical setting. ${ }^{[59]}$ Furthermore, students who possess an understanding of and integrate within an organization were found to cope or manage better when transitioning into a graduate nurse role. ${ }^{[58,60]}$ Watt and Pascoe ${ }^{[60]}$ point out that a lack of socialization to the organizational culture, knowledge and experience of organizational norms and values, contributes to the new graduate nurse's sense of lack of preparedness for practice.

\subsection{Challenges associated with the traditional model}

Participants identified six challenges associated with the traditional model: (a) managing large clinical groups, (b) missed learning opportunities, (c) limited time for teaching and supervision, (d) difficulty balancing student learning with patient safety, (e) being seen as visitors on the unit, and (f) lack of role preparation.

Missed learning opportunities. As pointed out elsewhere, supervising large clinical groups was the most frequently mentioned aspect of the traditional model that influenced both faculty and CIs' ability to facilitate student learning, and monitor and evaluate student clinical performance. These findings are consistent with previous research that found CIs were negatively impacted when instructing large groups, particularly in the acute care settings as it decreased time available for individual student-instructor interactions, ${ }^{[3,61,62]}$ and resulted in less or missed opportunities while students are waiting for the instructor. ${ }^{[3,7,13,17,36,63]}$

Limited time for teaching and supervision. Additionally, the high instructor-to-student ratio makes it difficult to spend adequate time with each student. CIs report spending most of their time supervising students performing skills which leaves little time for in-depth teaching and provision of feedback to students. ${ }^{[3,10]}$ A study conducted by Polifroni et al. ${ }^{[62]}$ revealed that during clinical time only $25 \%$ of a student's time was spent interacting with the CI or any other RN and the remaining $75 \%$ of the student's time was spent unsupervised. Other studies have reported that in the traditional model because of large clinical groups, struggling students are often able to "hide", as their difficulties may remain undetected and are not addressed in a timely manner. ${ }^{[36,64]}$

Published by Sciedu Press
Moreover, there are times when a CI has to supervise students in a number of units, which interferes with effective and timely supervision, as CI cannot be physically present with all the students at the same time. ${ }^{[16]}$ In the absence of their instructor students are encouraged to work closely with the RN who is caring for the patients to whom students have been assigned. ${ }^{[21]}$ This implies that the responsibility of supervising nursing skills such as medication administration, often, fall on the RNs on the units. ${ }^{[24,25]}$ This overreliance on RNs, however, not only overburdens already overworked staff, but has the potential to lead to resentment by those nurses who are not interested in working with students. ${ }^{[21]}$

Given the need for students to prepare for the full scope of practice as an $\mathrm{RN},{ }^{[2]}$ faculty and CIs must ensure that students are provided with opportunities to contextually experience complex skills such as decision making, delegation, and clinical reasoning. ${ }^{[61]}$ To reduce the challenges CIs encounter during clinical teaching, both faculty and CIs, like in previous studies ${ }^{[3,64,65]}$ recommended that the number of instructor-to-student ratio be moderated.

Limited time for teaching and supervision. Another related challenge identified was the need to work within time constraints. Consistent with findings from previous studies, participants in this study commented that large clinical groups make it difficult to simultaneously supervise all students and this can possibly compromise patient safety. ${ }^{[3,63]}$ Safe, quality patient care and quality student learning depend upon adequate supervision of nursing students throughout their clinical practice. Therefore, it is important that students receive the "best possible" supervision for them to become safe, competent and independent future health care practitioners and ensure safe practice while they learn to nurse. As Reid-Searl et al. ${ }^{[25]}$ noted, the impact of supervision must become a priority for research and practice in undergraduate nursing education programs.

CIs are increasingly concerned about patient safety as they work with nursing students in the acute care settings. ${ }^{[3,21]}$ They often cite a lack of time to effectively help students in processing rationale for nursing interventions. ${ }^{[3,10,61]}$ With large clinical groups, there exists the possibility of errors or safety issues especially during medication administration $^{[3,25]}$ or enactment of technical skills, due to inability of the CI to adequately monitor eight students simultaneously. As stated earlier, a study conducted by Reid-Searl et al. ${ }^{[25]}$ revealed that about a third of nursing students reported making an actual or "near miss" medication error during administration of drugs. Where the medication errors occurred, the students reported not receiving direct and appropriate supervision from a registered nurse or CI. From a 
nursing perspective, patient safety is not only a mandate, but it is part of the nurses' moral and ethical imperative when caring for others. ${ }^{[66]}$ In fact, according to $\mathrm{CNA}^{[67]}$ nurses are committed through the code of ethics to provide "safe, competent care" (p. 8). Nursing education programs have a responsibility to ensure that nursing students are exposed to the realities of the contemporary healthcare system and are prepared to practice with the competencies necessary to promote and preserve patient safety.

Being seen as visitors on the unit. Another challenge identified and supported by the literature was that faculty and students may not be treated as part of the clinical setting in which the students have clinical practice. ${ }^{[45,49]}$ As such faculty and students are seen as outsiders or visitors (guests) to the clinical setting and may not understand the system of care and the culture of the clinical setting. ${ }^{[45,49]}$ Roberts et al. ${ }^{[49]}$ found that CIs who were placed on units unfamiliar to them expressed stress and feelings of being overwhelmed. In addition, because they were unknown to the staff they did not have the same level of support when teaching students. Familiarity and relationships with the unit have been highlighted as a form of support for sessional CIs. ${ }^{[49]} \mathrm{Un}$ fortunately, in most cases, CIs are assigned to teach in areas where they do not have any experience or expertise. Hence, participants in the current study like in other studies recommended that whenever possible, sessional CIs should be assigned to teach in clinical settings where they have familiarity, experience, and expertise so that they can effectively facilitate quality student learning experiences. It is important, therefore, that both faculty and CIs develop a good working relationship with unit managers and clinical staff to ensure effective clinical learning experiences for students. ${ }^{[45]}$

Lack of role preparation. With regard to role preparation and training, most of the participants in this study reported that they had received no or very little formal preparation or support for their teaching and evaluation role. These findings corroborate evidence in the literature that nursing students are often taught by clinicians who in most cases have limited or no prior formal teaching background. ${ }^{[8,45,65]}$ It cannot be assumed that all clinically competent nurses can function effectively as clinical teachers. CIs must be well prepared with good nursing and teaching knowledge and experience. ${ }^{[68]}$ Furthermore, participants in this study remarked that despite the heavy workload of clinical teaching and evaluation, clinical teaching is not valued. They also believed that this was one of the main contributing factors to the high turnover of sessional CIs. This finding is also consistent with the literature. ${ }^{[3,45]}$

When faculty and CIs accept responsibility for clinical teach- ing nursing students, they accept some educational responsibilities including evaluation of student's clinical performance. By undertaking the role of an evaluator, both faculty and CIs are accountable to the learner, the nursing program, the profession, and by extension, society. Therefore, it is essential that both faculty and CIs are adequately prepared for this critical role, and that proper guidance and support be given, especially to new faculty and CIs. Despite these observations, almost all participants in this study were not well prepared for clinical teaching and particularly clinical evaluation. This finding is similar to those in prior studies. ${ }^{[8,46,65]}$ In reality many faculty and CIs learn on the job through experiential role performance, a finding implies that those who supervise and evaluate students may be insufficiently equipped for the role. $^{[65]}$

Difficulty balancing student learning with patient safety. Balancing complex patient needs with the learning needs of students is a major challenge for CIs. One of the major issues reported by participants was a perceived lack of time to perform their evaluation role effectively. This is consistent with the findings in the literature ${ }^{[69]}$ that CIs had insufficient time to dedicate to the evaluation process. Similarly, a study by Rafiee, Moattari, Nikbakht, Kojuri, and Mousavinasab ${ }^{[70]}$ revealed that nursing instructors were very busy during the semester and did not assign a specific time for evaluation and did not even have time to perform student final evaluation students at the end of the semester. Duffy, Stuart, and Smith ${ }^{[71]}$ asserted that part-time CIs encounter particular challenges in areas such as evaluating students, documenting student progress through the semester, and grading. Many other researchers have acknowledged that CIs, like preceptors need time to write complete accurate anecdotal records that substantiate awarding the clinical grade. ${ }^{[72,73]}$

\subsection{Recommendations for improving students' clinical learning experience}

Lastly, participants in the current study identified several recommendations to: (a) improve students' clinical learning experiences and (b) for enhancing their role in clinical teaching and evaluation of students learning, which are congruent with those in the literature and other studies. To improve students' clinical learning experiences, participants suggested, for example, reducing the instructor-to-student ratios to at least 1:6; hiring more experienced faculty; providing students with more clinical independence; and exposing students to a variety of clinical learning experiences, ${ }^{[3,57,64,68,74]}$ and introducing the preceptorship model early in the program. ${ }^{[17,57]}$ In order to improve the CI role in clinical teaching and evaluation of students learning, the participants recommended the following: assigning CIs to units on a more permanent basis; 
hiring more experienced CIs; providing formal orientation to all new CIs; providing ongoing support through professional development activities for both new and full-time faculty and CIs; providing mentorship for inexperienced CIs; pairing new CIs with experienced mentors; and providing mentorship in teaching material preparation and student assessment. These strategies concur with those in the literature. ${ }^{[8,46,65,68]}$

\section{Conclusion}

Although this exploratory study represents only one province in Western Canada, the findings affirm those reported in similar studies conducted in Canada ${ }^{[12]}$ and internationally. ${ }^{[3,10]}$
The study findings revealed that there are more challenges than strengths associated with the traditional model. The large clinical group size was the main challenge of the model resulting in limited time for teaching, supervision and evaluation of students, missed learning opportunities, and difficult balancing individual student learning. The findings of this study affirm the need for continuing research on clinical education, particularly on the effect of the duration of clinical placements and instructor-to-student ratios on student learning outcomes and patient safety.

\section{CONFlicts OF InTEREST Disclosure}

The author declares that there is no conflict of interest.

\section{REFERENCES}

[1] Canadian Association of Schools of Nursing. CASN Position Statement on the Education of Registered Nurses in Canada. Author: Ottawa. 2011. Available from: http://casn.ca/wp-content/u ploads/2014/10/EducationofRNsinCanadaEng.pdf

[2] The Institute of Medicine. The future of nursing: Leading change, advancing health. Washington, DC.: The National Academies Press; 2011.

[3] Benner P, Stephen M, Leonard V, et al. Educating nurses: A call for radical transforming. San Francisco: Jossey-Bass; 2010.

[4] Dyess SM, Parker C. Transition support for the newly licensed nurse: A program that made a difference. Journal of Nursing Management. 2012; 20(5): 615-623.

[5] Smadu M, McTeer M. The Health of Our Nation-The Future of Our Health System. 2012.

[6] Peters K, McInnes S, Halcomb E. Nursing students' experiences of clinical placement in community settings: a qualitative study. Collegian: The Australian Journal of Nursing Practice, Scholarship and Research. 2015; 22(2): 175-181.

[7] Canadian Association of Schools of Nursing. Clinical practice education survey 2003: CASN task force on clinical/practice education. 2004. Available from: http://casn.ca/wp-content/uploads /2014/12/ClinicalPracticeEducationSurvey2003.pdf

[8] Dahkle S, Baumbusch J, Aflfleck F, et al. The clinical instructor role in nursing education: A structured literature review. Journal of Nursing Education. 2012; 31(12): 692-698.

[9] Nielson AN, Noone J, Voss H, et al. Preparing nursing students for the future: an innovative approach to clinical education. Nurse Education in Practice. 2013; 13(4): 301-309.

[10] Ironside PM, McNelis AM. Clinical education in prelicensure nursing programs: findings from a national survey. Nursing Education Perspectives. 2010; 31(4): 264-265.

[11] Ironside PM, McNelis AM, Ebright P. Clinical education in nursing: Rethinking learning in practice. Nursing Outlook. 2014; 62(3): 185191. https://doi.org/10.1016/j.outlook. 2013.12.004

[12] Gregory D, Guse L, Dick DD, et al. The question of safety: An exploration of errors among undergraduate nursing students placed on clinical learning contracts. A Research Report Submitted to the Manitoba Institute for Patient Safety (MIPS). 2008.

[13] Tanner C. The next transformation: Clinical education. Journal of Nursing. 2006; 45(4): 99-100.
[14] Budgen C, Gamroth L. An overview of practice education models. Nurse Education Today. 2008; 28: 273-283. https ://doi .org/10 $.1016 / j$. nedt . 2007.05 .005

[15] Nehls N, Rather M, Guyette M. The preceptor model of clinical instruction: The lived experiences of students, preceptors, and faulty-of record. Journal of Nursing Education. 1997; 36: 220-227.

[16] Wotton K, Gonda J. Clinician and student evaluation of a collaborative clinical teaching model. Nurse Education in Practice. 2004; 4(5): 120-127.

[17] Beeman RY. New partnership between education and practice: Preceting junior nursing students in the acute care setting. Journal of Nursing Education. 2001; 40(3): 132-134.

[18] Hickey MT. Baccalaureate nursing graduates' perceptions of their clinical experience and preparation for practice. Journal of Professional Nursing. 2010; 26(1): 35-41. PMid:20129591 https: //doi.org/10.1016/j.profnurs.2009.03.001

[19] Emerson RJ. Nursing education in the clinical setting. St Louis, Missouri: Mosby/Elsevier; 2007.

[20] Delunas LR, Rooda LA. A model for the clinical instruction of undergraduate nursing students. Nursing Education Perspectives. 2009; 30(6): 377-380.

[21] Langan JC. Faculty practice and roles of staff nurses and clinical faculty in nursing student learning. Journal of Professional Nursing. 2003; 19(2): 76-84. PMid:12748932 https://doi.org/10.105 3/jpnu. 2003.17

[22] Henderson A, Cooke M, Creedy DK, et al. Nursing students' perceptions of learning in practice environments: A review. Nurse Education Today. 2012; 32(3): 299-302. https ://doi.org/10.1016/j.ne dt. 2011.03 .010

[23] Debrough GA, Prion SK. Patient safety manifesto: a professional imperative for prelicensure nursing education. Journal of Professional Nursing. 2012; 28(2): 110-118.

[24] Dolansky MA, Druschel K, Helba M, et al. Nursing student medication errors: A case study using root cause analysis. Journal of Professional Nursing. 2012; 29(2): 102-108.

[25] Reid-Searl K, Moxham L, Walker S, et al. Supervising medication administration by undergraduate nursing students: Influencing factors. Journal of Clinical Nursing. 2010; 19(5-6): 775-784.

[26] Reid-Searl K, Happell B. Supervising nursing students administering medication: A perspective from registered nurses. Journal of Clinical Nursing. 2012; 21(13-14): 1998-2005. 
[27] Wiens S, Babenko-Mould Y, Iwasiw C. Clinical instructors' perceptions of structural and psychological empowerment in academic nursing environments. Journal of Nursing Education. 2014; 53(5): 265 270. https ://doi.org/10.3928/01484834-20140421-01

[28] Canadian Nurses Association \& Canadian Association of Schools of Nursing. Nursing education in Canada statistics, 20092010 Registered Nurses workforce, Canadian production: Potential new supply. Author: Ottawa, ON. 2012. Available from: http://casn.ca/wp-content/uploads/2014/10/FIN ALNSFS20092010sENGJanuary252012Copy ·pdf

[29] Hewitt P, Lewallen LP. Ready, set, teach! How to transfer the clinical nurse expert into the part-time clinical nurse instructor. Journal of Continuing Education in Nursing. 2010; 41(9): 403-407. https://doi.org/10.3928/00220124-20100503-10

[30] Streubert HJ, Carpenter DR. Qualitative Research in Nursing: Advancing the Humanistic Imperative. Wolters Kluwer, Philadelphia.

[31] Braun V, Clarke V. Using thematic analysis in psychology. Qualitative Research in Psychology. 2011; 3(2): 77-101.

[32] Glaser BG. Theoretical sensitivity: Advanced in the methodology of grounded theory. Mill Valley, CA: Sociology Press; 1978.

[33] Guba EG, Lincoln YS. Fourth Generation Evaluation. Newbury Park, California: Sage; 1989.

[34] Houghton C, Cassey D, Shaw D, et al. Rigour in qualitative casestudy research. Nurse Research. 2013; 20(4): 12-17. https://doi . org/10.7748/nr2013.03.20.4.12.e326

[35] Lobiondo-Wood G, Haber J. Nursing research in Canada: Methods and critical appraisal for evidence-based practice (8th Ed.). Toronto, ON: Mosby/Evolve; 2013.

[36] Nishioka VM, Coe MT, Hanita M, et al. Dedicated education unit: Nurse perspectives on their clinical teaching role. Nursing Education Perspectives. 2014; 35(5): 294-300.

[37] Boughton MA, Halliday LE, Brown L. A tailored program of support for culturally and linguistically diverse (CALD) nursing students in a graduate entry. Masters of Nursing course: A qualitative evaluation of outcomes. Nurse Education in Practice. 2010; 10(6): 355-360. https://doi.org/10.1016/j.nepr.2010.05.003

[38] Starr K. Nursing education challenges: Students with English as an additional language. Journal of Nursing Education. 2009; 48(9): 478486. https : //doi.org/10.3928/01484834-20090610-01

[39] Bosher S, Smalkoski K. From needs analysis to curriculum development: Designing a course in healthcare communication for immigrant students in the USA. English for Specific Purposes. English for Specific Purposes. 2002; 21: 59-79. https ://doi.org/10.1016/S0 889-4906 (01) 00002-3

[40] San Miguel C, Rogan F, Kilstoff K, et al. Clinically speaking: A communication skill program for students from non-English speaking background. Nurse Education in Practice. 2006; 6(5): 268-274.

[41] Bourgeois S, Drayton N, Brown AM. An innovative model of supportive clinical teaching and learning for undergraduate nursing students: The cluster model. Nurse Education in Practice. 2011; 11(2): 114-118. https://doi.org/10.1016/j.nepr.2010.11.005

[42] Stone R, Cooper S, Cant R. The value of peer learning in undergraduate nursing education: A systematic review. ISRN Nursing. 2013. http://dx.doi.org/10.1155/2013/93090

[43] Stenberg M, Carlson E. Swedish student nurses' perception of peer learning as an educational model during clinical practice in a hospital setting-an evaluation study. BMC Nursing. 2015; 14(48): 1-7. https://doi.org/10.1186/s12912-015-0098-2

[44] Chojecki P, Lamarre J, Buck M, et al. Perceptions of a peer learning approach to pediatric clinical education. International Journal of Nursing Education Scholarship. 2010. https : //doi .org/10. 220 2/1548-923X. 1893
[45] Gaberson K, Oermann MH, Shellenbarger T. Clinical strategies in nursing. (4th ed.). New York, NY: Springer Publishing; 2015.

[46] Davidson KM, Rourke L. Surveying the orientation learning needs of clinical nursing instructors. International Journal of Nursing Education Scholarship. 2012; 9(1): Article 3. https ://doi .org/10.1 515/1548-923X. 2314

[47] Vandyk A, Chartrand J, Beke E, et al. Perspectives from Academic Leaders of the Nursing Faculty Shortage in Canada. International Journal of Nursing Education Scholarship. 2017; 14(1). https://doi .org/10.1515/ijnes-2017-0049

[48] Dahlke S, O'Connor M, Hannesson T, et al. Understanding clinical nursing education: An exploratory study. Nursing Education in Practice. 2016; 17: 145-152.

[49] Roberts KK, Chrisman SK, Flowers C. The perceived needs of nurse clinicians as they move into an adjunct clinical faculty role. Journal of Professional Nursing. 2013; 29(5): 295-301. https : //doi.org/10.1016/j.profnurs.2012.10.012

[50] Gazza EA, Shellenbarger T. The lived experience of part-time baccalaureate nursing faculty. Journal of Professional Nursing. 2010; 26(6): 353-359.

[51] Babenko-Mould Y, Iwasiw CL, Andrusyszyn M, et al. Nursing students' perceptions of clinical teachers' use of empowering teaching behaviours: Instrument psychometrics and application. International Journal of Nursing Education Scholarship. 2012; 9(1): 1-15. PMid:22499715 https ://doi.org/10.1515/1548-923X . 2245

[52] Bryan V, Weaver S, Anderson-Johnson P, et al. The effect of interpersonal relationships between nursing students and lecturers on learning outcomes at a Jamaican nursing school. Caribbean Journal of Nursing. 2013; 1(1): 41-48.

[53] Houghton CE, Casey D, Shaw D, et al. Students' experiences of implementing clinical skills in the real word of practice. Journal of Clinical Nursing. 2013; 22(13-14): 1961-1969.

[54] Brown L, Herd K, Gwynneth H, et al. The role of the lecturer in practice placements: what do students think? Nurse Education in Practice. 2005; 5(2): 84-90. PMid:19038184 https://doi.org/ $10.1016 / j$.nepr.2004.03.006

[55] Damodaran DP, Kandasamy M. Clinical Environment: Experiences of Undergraduate Student Nurses. International Journal of Advances in Nursing Management. 2013; 1(1): 26-30.

[56] O’Mara L, McDonalda J, Gillespie M, et al. Challenging clinical learning environments: experiences of undergraduate nursing students. Nurse Education in Practice. 2014; 14(2): 208-13. PMid:24063792 https://doi.org/10.1016/j.nepr. 2013.08 .012

[57] Nordgren J, Richardson SJ, Laurella VB. A collaborative preceptor model for teaching of beginning nursing students. Nurse Educator. 1998; 23: 27-32. https://doi.org/10.1097/00006223-19980 5000-00013

[58] Newton JM, Cross WM, White K, et al. Outcomes of a clinical partnership model for undergraduate nursing students. Contemporary Nurse. 2011; 39(11): 119-128. PMid:21955272 https : //doi.org/10.5172/conu.2011.39.1.119

[59] Patterson EEB, Boyd L, Mnatzaganian G. The impact of undergraduate clinical teaching models on the perceptions of work-readiness among new graduate nurses: A cross sectional study. Nurse Education Today. 2017; 55: 101-106. PMid:28575706 https://doi .or g/10.1016/j.nedt. 2017.05 .010

[60] Watt E, Pascoe E. An exploration of graduate nurses' perceptions of their preparedness for practice after undertaking the final year of their bachelor of nursing degree in a university-based clinical school of nursing. International Journal of Nursing Practice. 2013; 19(1): 23-30. PMid:23432885 https : //doi.org/10.1111/ijn. 12032 
[61] McNelis AM, Ironside PM, Ebright PR, et al. Learning nursing practice: A multisite, multimethod investigation of clinical education. Journal of Nursing Regulation. 2014; 4(4): 30-35. https: //doi.org/10.1016/S2155-8256(15) 30115-0

[62] Polifroni EC, Packard SA, Shah HS, et al. Activities and interactions of baccalaureate nursing students in clinical practica. Journal of Professional Nursing. 1995; 11(3): 161-169. https://doi.org/10.1 016/S8755-7223(95) 80115-4

[63] Maguire DJ, Zambroski CH, Cadena SV. Using collaborative model for nursing education. Nurse Educator. 2012; 37(2): 80-85. PMid:22327534 https://doi.org/10.1097/NNE.0b013e3182 $461 \mathrm{bb} 6$

[64] Killam LA, Heerschap C. Challenges to student learning in the clinical setting: A qualitative descriptive study. Nurse Education Today. 2013; 33(6): 684-691. PMid:23141689 https://doi.org/10.1 $016 / j$.nedt $.2012 \cdot 10.008$

[65] Eta VE, Atanga MB, Atashilli J, et al. Nurses and challenges faced as clinical educators: A survey of a group of nurses in Cameroon. The Pan African Medical Journal. 2011; 8(28).

[66] Canadian Nurses Association. Position Statement: Patient safety. Ottawa, ON: Author. 2009. Available from: https://www.cna-aiic.ca/ /media/cna/page-content/p df-en/ps102_patient_safety_e.pdf?la=en

[67] Canadian Nurses Association. Code of ethics for registered nurses. Ottawa, ON, Author. 2010. Available from: https://cna-aii c.ca/ /media/cna/page-content/pdf-en/code-of-ethic s-2017-edition-secure-interactive.pdf?la=en

[68] Mathew-Maich N, Martin L, Ackerman-Rainville R, et al. Student perceptions of effective nurse educators in clinical practice. Nursing Standard. 2015; 29(34): 45-52. PMid:25902252 https : //doi.org/10.7748/ns.29.34.45.e9640

[69] DeMesteer DA. The Meaning of the Lived Experience of Nursing Faculty on a Dedicated Education Unit. PhD Thesis, University of Nevada, Las Vegas. 2012.

[70] Rafiee G, Moattari M, Nikbakht AN, et al. Problems and challenges of nursing students' clinical evaluation: A qualitative study. Iranian Journal of Nursing and Midwifery Research. 2014; 19(1): 41-49.

[71] Duffy N, Stuart G, Smith S. Assuring the success of part-time faculty. Nurse Educator. 2008; 33: 53-54. PMid:18317311 https: //doi.org/10.1097/01.NNE.0000299502.09658.97

[72] Luhanga F, Yonge O, Myrick F. "Failure to assign failing grades": Issues with grading the unsafe students. International Journal of Nursing Education Scholarship. 2008; 5(1): 1-14. PMid:18384275 https ://doi.org/10.2202/1548-923X.1366

[73] Walsh CM, Seldomridge LA. Clinical grades: Upward bound. Journal of Nursing Education. 2005; 44(4): 162-168. PMid:15862049

[74] Löfmark A, Wikblad K. Facilitating and obstructing factors for development of learning in clinical practice: a student perspective. Journal of Advanced Nursing. 2001; 34(1): 43-50. https: //doi.org/10.1046/j.1365-2648.2001.3411739.x 